\title{
Increased availability of NADH in metabolically engineered baker's yeast improves transaminase-oxidoreductase coupled asymmetric whole-cell bioconversion
}

\author{
Jan Dines Knudsen ${ }^{1,2}$, Cecilia Hägglöf ${ }^{1}$, Nora Weber ${ }^{1,3}$ and Magnus Carlquist ${ }^{*}$
}

\begin{abstract}
Background: Saccharomyces cerevisiae can be engineered to perform a multitude of different chemical reactions that are not programmed in its original genetic code. It has a large potential to function as whole-cell biocatalyst for one-pot multistep synthesis of various organic molecules, and it may thus serve as a powerful alternative or complement to traditional organic synthetic routes for new chemical entities (NCEs). However, although the selectivity in many cases is high, the catalytic activity is often low which results in low space-time-yields. In the case for NADHdependent heterologous reductive reactions, a possible constraint is the availability of cytosolic NADH, which may be limited due to competition with native oxidative enzymes that act to maintain redox homeostasis. In this study, the effect of increasing the availability of cytosolic $\mathrm{NADH}$ on the catalytic activity of engineered yeast for transaminationreduction coupled asymmetric one-pot conversion was investigated.
\end{abstract}

Results: A series of active whole-cell biocatalysts were constructed by over-expressing the (S)-selective $\omega$-transaminase (VAMT) from Capsicum chinense together with the NADH-dependent (S)-selective alcohol dehydrogenase $(S A D H)$ originating from Rhodococcus erythropolis in strains with or without deletion of glycerol-3-phosphate dehydrogenases 1 and 2 (GPD1 and GPD2). The yeast strains were evaluated as catalysts for simultaneous: (a) kinetic resolution of the racemic mixture to $(R)$-1-phenylethylamine, and $(b)$ reduction of the produced acetophenone to (S)-1-phenylethanol. For the gpd1 $\triangle g p d 2 \Delta$ strain, cell metabolism was effectively used for the supply of both amine acceptors and the co-factor pyridoxal-5'-phosphate (PLP) for the $\omega$-transaminase, as well as for regenerating NADH for the reduction. In contrast, there was nearly no formation of (S)-1-phenylethanol when using the control strain with intact GPDs and over-expressing the VAMT-SADH coupling. It was found that a gpd1 $\triangle g p d 2 \triangle$ strain over-expressing $S A D H$ had a 3 -fold higher reduction rate and a 3-fold lower glucose requirement than the strain with intact GPDs overexpressing SADH.

Conclusions: Overall the results demonstrate that the deletion of the GPD1 and GPD2 genes significantly increases activity of the whole-cell biocatalyst, and at the same time reduces the co-substrate demand in a process configuration where only yeast and sugar is added to drive the reactions, i.e. without addition of external co-factors or prosthetic groups.

Keywords: Whole-cell biocatalysis, Co-factor regeneration, Chiral amines, Chiral alcohols, Glycerol-3-phosphate dehydrogenase, Kinetic resolution, (R)-1-phenylethylamine, (S)-1-phenylethanol

\footnotetext{
*Correspondence: magnus.carlquist@tmb.lth.se

' Division of Applied Microbiology, Department of Chemistry, Faculty

of Engineering, Lund University, PO Box 124, 22100 Lund, Sweden

Full list of author information is available at the end of the article
} 


\section{Background}

Chiral amines and chiral alcohols are important functional moieties in many bioactive compounds and they are essential for completing total synthesis of various drugs [1]. There is thus a need for economically and environmentally sustainable methods for their preparation. Chiral amines and alcohols can be generated enzymatically from ketones by the action of $\omega$-transaminases $(\omega$-TAs) $[2,3]$ and ketone reductases (KREDs) [4], respectively. $\omega$-TAs require the prosthetic group pyridoxal-5'-phosphate (PLP) for functionality and also a sufficient supply of amine acceptor or amine donor molecules depending on the mode of operation, i.e. kinetic resolution of racemic amines or direct amination of ketones. In most described biocatalytic transaminations, the required enzymes, PLP and amine acceptors/ donors have been directly added to the reaction mixture [5]. Similarly, asymmetric reduction of ketones to chiral alcohols by KREDs require addition of the cofactor $\mathrm{NADH}$ or NADPH and a system for hydride recycling, e.g. by the action of formate dehydrogenase or glucose dehydrogenase.

Coupled transamination and reduction reactions can be used for conversion of alcohols to amines or for the reverse reaction, i.e. amines to alcohols, and are useful tools in the organic synthetic toolbox for functional modification and synthesis of new chemical entities (NCEs). The coupled two-step reactions can be catalysed in onepot by living microbial cells that co-express the required enzymes and use cell metabolism for (re-)generation of co-factors, prosthetic groups, and essential co-substrates. Other strongholds of using microbial cells as catalysts include high selectivity, renewable origin and a simplified upstream processing, as well as operation under relatively mild and environmentally benign conditions [6]. In line with this, one-pot conversion of 1,10-decanediol to 1,10-diaminedecane was recently achieved in engineered Escherichia coli strains co-expressing alcohol dehydrogenase, transaminase, and alanine dehydrogenase [7]. Baker's yeast Saccharomyces cerevisiae was previously engineered for kinetic resolution of racemic 1-phenylethylamine to $(R)$-1-phenylethylamine and simultaneous reduction of the formed acetophenone to $(R)$-1-phenylethanol [8]. The reactions were catalysed in vivo by a recombinant $\omega$-TA from Capsicum chinense co-expressed with a recombinant NADPH-dependent alcohol dehydrogenase from Lactobacillus kefir. Both PLP and amine acceptors (for example pyruvate) for the $\omega$-TA [9], as well as NADPH for the oxidoreductase [8] was previously shown to be possible to provide from cell metabolism. However, the engineered yeast biocatalysts suffered from low specific activity which leads to high loadings of yeast and sugar in order to reach high conversions.
A possible limiting factor for KRED-based reaction cascades is the availability of intracellular $\mathrm{NAD}(\mathrm{P}) \mathrm{H}[10$, 11]. To increase the availability of NADPH, a number of in vivo systems in which the cellular carbon metabolism is used to fuel the oxidation-reduction cycle have been developed [12, 13]. For example, metabolically engineered S. cerevisiae with increased flux through the pentose-phosphate pathway resulting in an increased availability of NADPH for recombinant oxidoreductases have been described [14]. The NADPH platform was successfully used with different NADPH-dependent KREDs for preparative-scale production of chiral alcohols via whole-cell bioconversion of prochiral ketones $[10,15]$ or from the racemic mixtures $[11,16]$. Other recent examples of engineered whole-cell systems in which the native cell metabolism was re-wired for an increased availability of NADPH is the cyclised pentose-phosphate pathway system in Corynebacterium glutamicum [17] and the elevated activity of transhydrogenase and $\mathrm{NAD}^{+}$kinase in E. coli [18].

With regards to NADH in baker's yeast, the NADH formed in the glycolysis during fermentative or respirefermentative mode of metabolism is oxidized by alcohol dehydrogenases (ADHs) that catalyse the reduction of acetaldehyde to ethanol. Under oxygen-limited conditions, the additional cytosolic NADH formed from anabolic reactions such as during amino acid biosynthesis is oxidized by glycerol-3-phosphate dehydrogenase (GPD) isoenzymes 1 and 2, which catalyse the reduction of dihydroxyacetone phosphate (DHAP) to glycerol-3-phosphate $[19,20]$. Thus, to fully exploit the cellular capacity to regenerate NADH required for whole-cell biocatalytic reactions, there may be a need to deactivate native $\mathrm{NADH}$ oxidating enzymes. It has previously been demonstrated that the limited capacity to oxidize NADH in gpd $1 \Delta g p d 2 \Delta$ strain can be exploited to achieve higher formation of xylitol [21, 22] and butanol [23].

In this study, the suitability of $g p d 1 \Delta g p d 2 \Delta$ yeast to function as platform host for whole-cell biocatalytic transaminase-reductase coupled reactions was evaluated. For this purpose, the use of gpd1 1 gpd $2 \Delta$ yeast for simultaneous preparation of chiral $(R)$-1-phenylethylamine and chiral (S)-1-phenylethanol from the racemic amine (Additional file 1: Figure S1) was compared to strains with intact GPD. (R)-1-phenylethylamine and $(S)$ 1-phenylethanol are important synthons for production of various bioactive molecules, and their preparation by whole-cell biocatalysis offers an attractive alternative to chemical synthesis [8]. Herein, the whole-cell biocatalytic activity, NADH regeneration rate, glucose demand, and general physiological response of the engineered gpd $1 \Delta$ gpd $2 \Delta$ yeast also over-expressing a recombinant $\omega$-TA and a KRED are discussed. 


\section{Results}

Construction of whole-cell biocatalysts with over-expressed VAMT and SADH

Native $S$. cerevisiae does not possess any background transaminase activity for $(S)$ - or $(R)$-1-phenyethylamine [9], and only a very limited activity for the reduction of acetophenone to (S)-1-phenylethanol by endogenous oxidoreductases [8]. A series of active $S$. cerevisiae whole-cell biocatalysts were therefore constructed by over-expressing synthetic codon-optimized genes encoding an $(S)$-selective $\omega$-TA from $C$. chinense (vanillin aminotransferase, VAMT) [24] coupled to a NADHdependent $(S)$-selective alcohol dehydrogenase (SADH) from Rhodococcus erythropolis [25]. VAMT and SADH were chosen based on their substrate specificity and that they have previously been shown to have excellent enantio-selectivity; VAMT for the conversion of $(S)$-1-phenylethylamine to acetophenone [24] and SADH for the conversion of acetophenone to (S)-1-phenylethanol [25]. In the case of VAMT, it has also previously been shown to be active in $S$. cerevisiae for the reaction under investigation herein $[8,9]$.

The codon-optimized synthetic gene coding for SADH was cloned into a yeast integrative plasmid (YIp) either alone or in combination with the codon-optimized synthetic gene encoding VAMT. SADH and VAMT were cloned downstream of the PGK1 and TDH3 promoters, respectively, which are known to be constitutive and highly expressed [26]. The YIp-constructs with only $S A D H$ (YIpOB7-SADH) or with both $S A D H$ and VAMT (YIpOB7-SADH-VAMT) were transformed in S. cerevisiae CEN.PK background strains (TMB4132 and TMB4133) with intact or deleted GPD1 and GPD2 genes, resulting in four different active whole-cell biocatalysts (TMB4160-TMB4163) (Table 1). Two additional strains (TMB4140 and TMB4144) with the empty plasmids were also used as negative controls to determine background activity of endogenous enzymes.

\section{Evaluation of the effect of GPD deletion on acetophenone reduction by strains expressing SADH}

The effect of deleting the GPD1,2 genes on the bioreduction step was first evaluated in strains over-expressing only SADH (TMB4160 and TMB4161). Cells were grown in aerobic batch mode in shake flasks and harvested in early stationary phase. The cell biomass was subsequently used for whole-cell bioconversion of acetophenone to (S)-1-phenylethanol in small-scale glass vials sealed with rubber stoppers to ensure fermentative metabolism. The reaction solution was based on a defined mineral medium with an excess of glucose $(50 \mathrm{~g} / \mathrm{l})$ to allow for cell growth and thus generation of NADH from anabolic reactions. Sealing of the reaction vessels led to a fast consumption of the initially available oxygen which consequently resulted in an oxygen-limited environment and thus a strong need for NADH oxidation via the glycerol biosynthesis pathway.

The conversion of acetophenone to $(S)$-1-phenylethanol was approximately 2 -fold higher for the gpd1 $1 \Delta p d 2 \Delta$ strain over-expressing $S A D H$ (TMB4161) as compared to the control strain with intact GPD-genes (TMB4160) (Fig. 1a). The same trends were observed when comparing the whole-cell bioreduction of acetophenone catalysed by strains over-expressing both VAMT and $S A D H$ TMB4162-63 (3-fold higher activity in the gpd1 $g p d 2 \Delta$ strain) (Fig. 1b, Table 2).

Table 1 Plasmids and strains used in the study

\begin{tabular}{|c|c|c|c|}
\hline Strain and plasmids & Relevant genetic features & Description & Reference \\
\hline \multicolumn{4}{|l|}{ Plasmids } \\
\hline Ylplac211 & URA3 & & {$[39]$} \\
\hline YlpOB7 & URA3 PGK1p-XYL2-PGK1t, TDH3p-ADH1t & & {$[31]$} \\
\hline YIpOB7-SADH & URA3 PGK1p-SADH-PGK1t & & This study \\
\hline YIpOB7-SADH-VAMT & URA3 PGK1p-SADH-PGK1t, TDH3p-VAMT-ADH1t & & This study \\
\hline \multicolumn{4}{|l|}{ S. cerevisiae strains } \\
\hline TMB4132 & CEN.PK2-1C his3::YlpJK01 trp 1::TRP1 leu2::LEU2 ura3- & & {$[21]$} \\
\hline TMB4133 & CEN.PK2-1C his3::YIpJK01 gpd1::TRP1 gpd2:LEU2 ura3- & & {$[21]$} \\
\hline TMB4140 & TMB4132 ura3:: Ylplac211 & Empty plasmid & {$[21]$} \\
\hline TMB4144 & TMB4133 ura3:: Ylplac211 & Empty plasmid, gpd1 1 gpd2 $\Delta$ & {$[21]$} \\
\hline TMB4160 & TMB4132 ura3::YIpOB7-SADH & $S A D H$ & This study \\
\hline TMB4161 & TMB4133 ura3::YIpOB7-SADH & $S A D H, g p d 1 \triangle g p d 2 \triangle$ & This study \\
\hline TMB4162 & TMB4132 ura3::YlpOB7-SADH-VAMT & VAMT and SADH & This study \\
\hline TMB4163 & TMB4133 ura3::YIpOB7-SADH-VAMT & VAMT and SADH, gpd1 $\triangle g p d 2 \triangle$ & This study \\
\hline
\end{tabular}




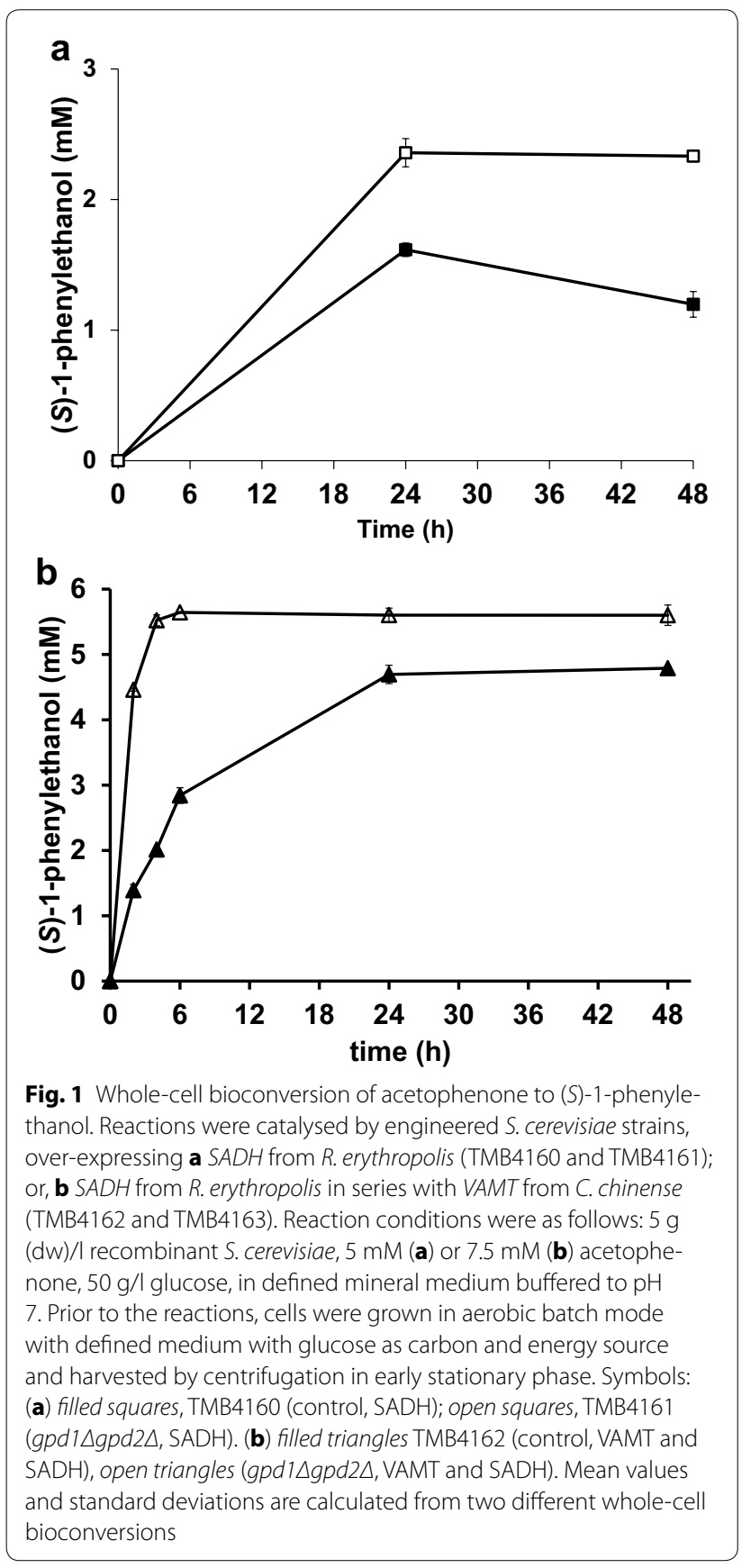

After $6 \mathrm{~h}$ of whole-cell bioconversion of acetophenone, the concentration of (S)-1-phenylethanol was approximately $5.7 \mathrm{mM}$ and $2.8 \mathrm{mM}$ for the gpd1 1 gpd $2 \Delta$ (TMB4163) and control (TMB4162) strains, respectively. The enantiomeric excess (ee) of the produced alcohol was $>99 \%$ for all $S A D H$ over-expression strains, indicating limited competing activity from endogenous KREDs with opposite selectivity. This was also demonstrated by an neglectable conversion of acetophenone with the negative control strain (TMB4132) lacking $S A D H$ (data not shown), which is in accordance with a previously performed study [8]. The substantially higher reductase activity in cell extracts of strains over-expressing $S A D H$ as compared to the background activity of native reductases (for example YMR226c, [27]) was confirmed by enzyme activity measurements (Table 2). It is noteworthy that although the activity in cell extract was more than 2-fold higher for the control strain (TMB4160) as compared to the $g p d 1 \Delta g p d 2 \Delta$ strain (TMB4161), the rate of reaction with the metabolically active whole-cell biocatalysts displayed the reversed order of activity, i.e. the conversion with whole-cells was 2 -fold higher for the gpd1 $\operatorname{gpd} 2 \Delta$ strain. This indicated that the higher catalytic activity in the gpd1 $\operatorname{gpd} 2 \Delta$ strain did not result from a higher Sadhp level, but was indeed ascribed to a higher availability of NADH for the reaction in that strain. Additionally, a similar effect was observed when VAMT gene was present for TMB4162 (VAMT and SADH) and TMB4163 (VAMT and SADH, gpd1 1 gpd2 $\Delta$ ), i.e. the double deletion strain displayed 3-fold higher reductase activity than the control strain (Fig. 2). However, in addition to the increased availability of $\mathrm{NADH}$ in the gpd1 1 gpd $2 \Delta$ strain (TMB4163), a 2-fold higher specific reductase activity in cell extract was also measured (Table 2).

\section{Whole-cell bioconversion of racemic 1-phenylethylamine to (S)-1-phenylethanol in strains over-expressing SADH and VAMT}

The effect of deleting GPD1,2 on the two-step conversion of $(S)$-1-phenylethylamine enantiomer of the racemic amine into acetophenone and then further to $(S)$-1-phenylethanol (Additional file 1: Figure S1) was evaluated. Whole-cell bioconversions of $5 \mathrm{mM}$ racemic 1-phenylethylamine were performed under similar conditions as described above, e.g. in defined mineral medium, anoxic conditions, and with an excess $(50 \mathrm{~g} / \mathrm{l})$ of glucose. Thus, under the applied process conditions, glucose was the sole co-substrate to supply NADH for carbonyl reduction, as well as to supply amine acceptor (for example pyruvate), and the essential prosthetic group PLP for the transamination reaction [9].

The resolution of the racemate to $(R)$-1-PEA was very low for the yeast strain with intact GPD-genes as catalyst (TMB4162) (Fig. 2a), and only a limited conversion of the racemate was obtained (4\% conversion and $4 \%$ $e e$ of $(R)$-1-PEA after $24 \mathrm{~h}$ ). This is in agreement with the $5 \%$ conversion that was observed earlier in a similar background strain only carrying the $V A M T$ and where the reaction configurations was with growing cells [8]. The $e e$ was however significantly higher than when using control yeast strains as catalyst, since without the expression of VAMT there is no conversion at all (Table 2). In 


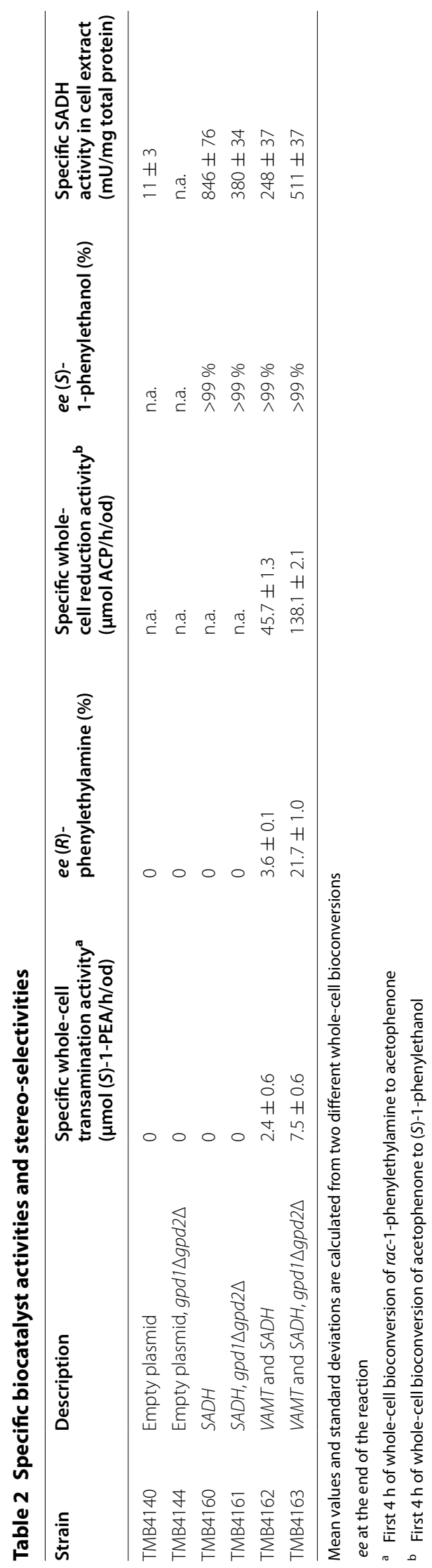




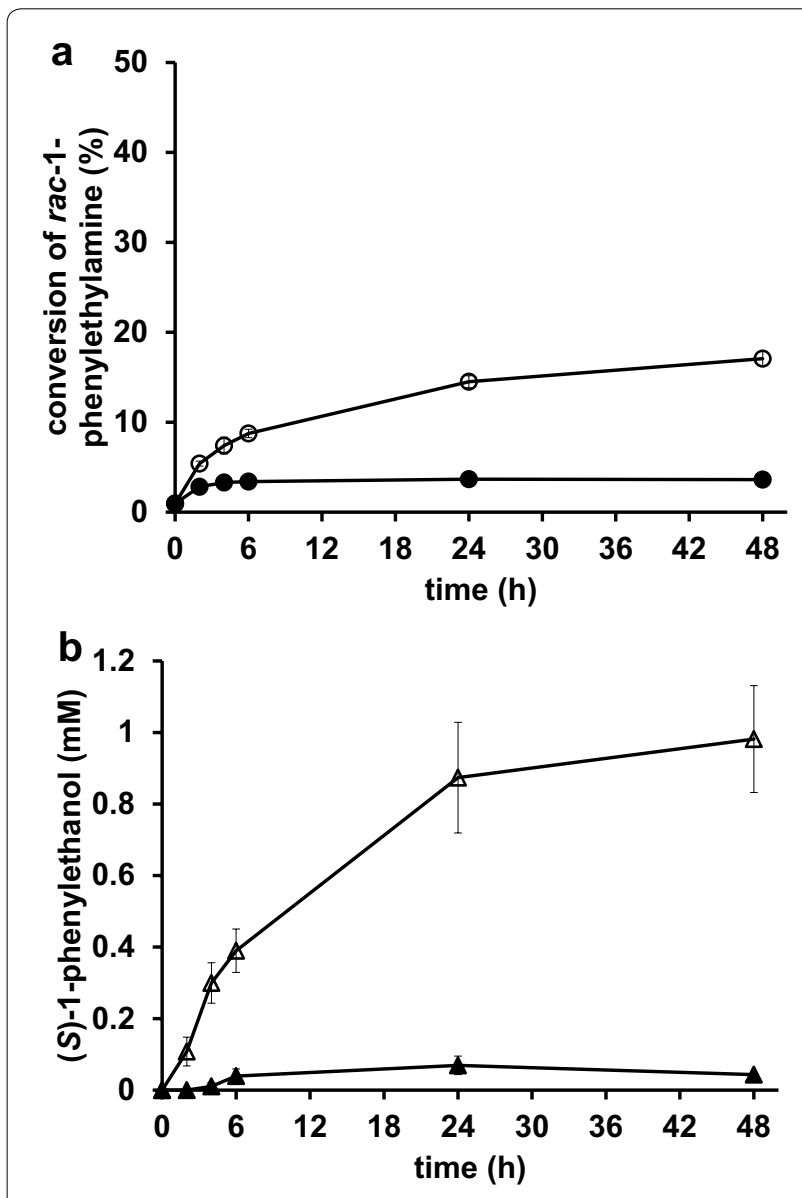

Fig. 2 Whole-cell bioconversion of racemic 1-phenylethylamine to $(R)$-1-phenylethylamine and (S)-1-phenylethanol with cells over-expressing both SADH and VAMT encoding genes. a Conversion (\%) of (S)-1-phenylethylamine, and $\mathbf{b}$ concentration (mM) of (S)-1-phenylethanol during whole-cell biotransformation of racemic 1-phenylethylamine. Reactions were catalysed using recombinant S. cerevisiae strains over-expressing SADH from $R$. erythropolis and VAMT from C. chinense, and having native (TMB4162) (filled symbols) or deleted (TMB4163) (open symbols) glycerol-3-phosphate dehydrogenase (GPD) activity. Reaction conditions were as follows: $5 \mathrm{~g}$ $(\mathrm{dw}) / \mathrm{I}$ recombinant $\mathrm{S}$. cerevisiae, $5 \mathrm{mM}$ racemic 1-phenylethylamine, $50 \mathrm{~g} / \mathrm{l}$ glucose, in a defined mineral medium buffered to $\mathrm{pH}$ 7. S. cerevisiae was grown in aerobic batch mode in stirred tank reactors with defined media with glucose as carbon and energy source and harvested by centrifugation in early stationary phase. Mean values and standard deviations are calculated from two different whole-cell bioconversions

summary, this demonstrates that the over-expressed recombinant transaminase was active, although to a relatively low degree. The stereo-selectivity was however high and no conversion of the $R$-enantiomer was detected in any of the experiments made throughout this study, which is in agreement with a previously performed characterization of the enzyme [24]. The low conversion of the amine resulted in formation of acetophenone below the limit of detection and a concentration of $(S)$ 1-phenylethanol below $0.1 \mathrm{mM}$ for the control strain (Fig. 2b). This low reaction rate might have been caused by product inhibition of the enzyme, however the acetophenone concentrations obtained were well below the concentration where acetophenone has previously been shown to inhibit VAMT (5 mM) [8]. The low conversion was therefore more likely explained by a low VAMT level and/or limitation in available PLP, since this has been shown previously to influence whole-cell biocatalytic transamination activity [9].

For the $g p d 1 \Delta g p d 2 \Delta$ strain (TMB4163), the specific whole-cell transamination activity was 3-fold higher as compared to the strain with intact GPD (TMB4162), resulting in a more efficient kinetic resolution (18\% conversion and $22 \% e e$ after $48 \mathrm{~h}$ ), and a final concentration of (S)-1-phenylethanol of approximately $1 \mathrm{mM}$ (Fig. 2ab). The two strains contained the same number of gene copies as determined with qPCR (data not shown). Hence, the difference in activity may therefore not be due to different levels of the recombinant transaminase but rather to a more efficient reduction step.

\section{Glucose assimilation and regeneration of NADH during reaction progress}

In accordance with previous studies [21, 28] the rate of sugar consumption differed significantly between the gpd1 $\operatorname{gpd} 2 \Delta$ strain and the control strain (Fig. 3a; Table 3). The gpd1 $\operatorname{spd} 2 \Delta$ strain consumed glucose at a 3 -fold lower rate than the control strain $(29 \mathrm{mM} / \mathrm{h}$ vs. $74 \mathrm{mM} / \mathrm{h}$ ). At the same time the reduction of acetophenone to phenylethanol (Fig. 1) occurred at a higher rate in that strain (Table 2), leading to a higher co-substrate yield for the reduction as compared to the control $\left(\mathrm{Y}_{\mathrm{P} / \mathrm{S}}=0.05 \mathrm{vs} 0.01 \mathrm{mmol}\right.$ chiral alcohol produced $/ \mathrm{mmol}$ glucose consumed, respectively). The rate of NADH generated from glucose through glycolysis and regenerated via ethanol, glycerol, and 1-phenylethanol production was estimated from their specific production and consumption rates (Table 2). Most of the NADH produced in glycolysis was oxidized by yeast native alcohol dehydrogenase resulting in a significant ethanol production for both strains (Fig. 3a and Table 3). Nevertheless, the ethanol concentration for the gpd1 $1 \operatorname{gpd} 2 \Delta$ strain was significantly lower than for the control, which may have implications for potentially adverse synergistic effect with toxic substrates/products.

Cell growth rate during whole-cell conversion of acetophenone was approximately 2-fold higher for the wild type strain than the double deletion strains (Fig. 3b, Table 3). Furthermore, growth arrested after approximately $6 \mathrm{~h}$ of reaction which in the case of the wild type strain coincided with glucose depletion. For the 


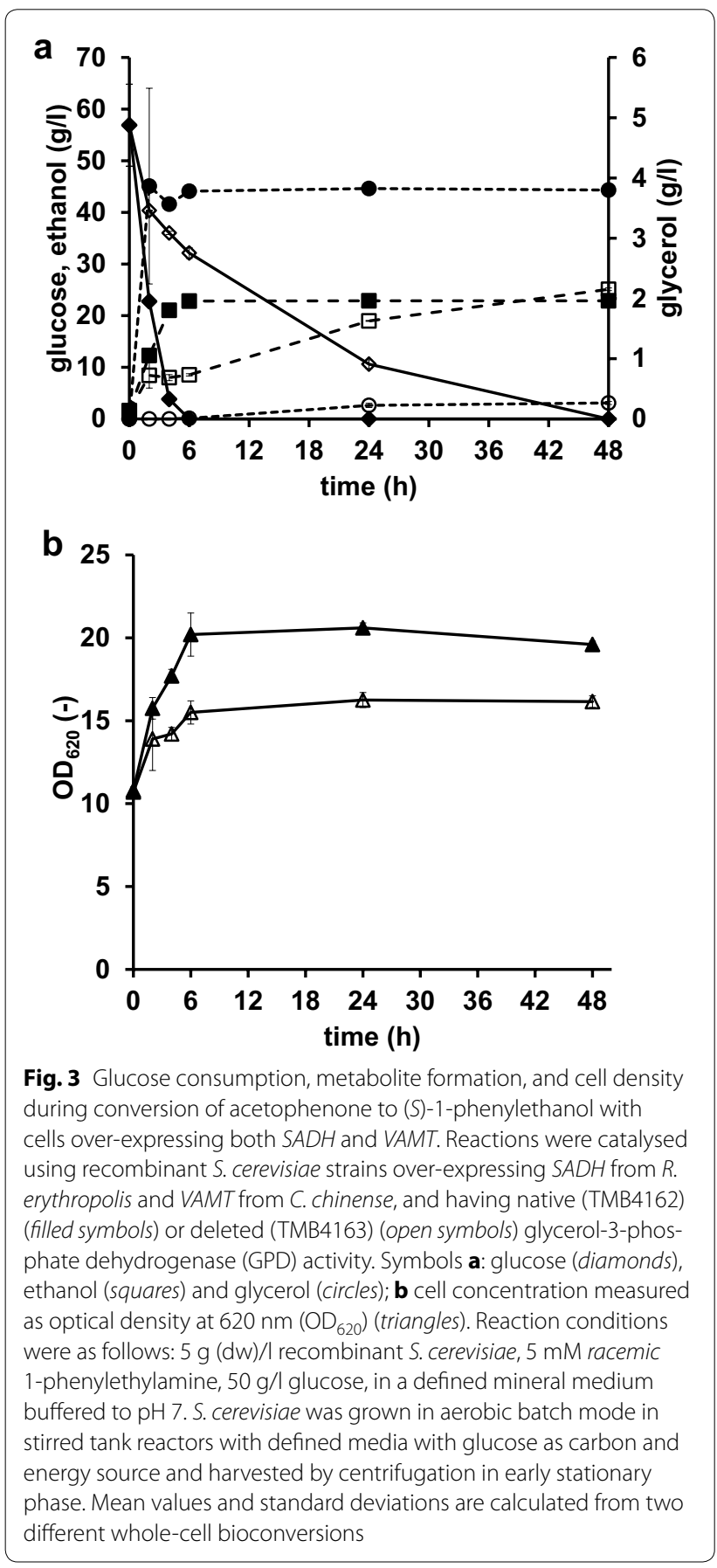

gpd $1 \Delta g p d 2 \Delta$ strain there was still $>30 \mathrm{~g} / \mathrm{l}$ of glucose left in the solution and the arrest in growth was instead related to lack of oxygen in the bioreactor. This was in accordance to previous studies where it has been shown that the capacity to proliferate depends on the capacity to oxidize NADH $[20,22]$. Nevertheless, growth was not sustained but there was still a significant degree of glucose consumption (Fig. 3a) and thus a significant
NADH regeneration throughout the course of reaction (24-48 h).

In fact, the presence of acetophenone or racemic 1-phenylethylamine did not influence growth rate or glucose consumption rate during the reactions for any of the strains. With this follows that the substrates were not added at an inhibitory concentration. Furthermore, it also demonstrates that the increased $\mathrm{NADH}$ oxidation caused by the SADH-catalysed reduction of acetophenone was insufficient to compensate for the lack of NADH oxidation by GPD1 and GPD2 and thereby insufficient to restore the poor growth of $g p d 1 \Delta g p d 2 \Delta$ strain under oxygen-limited conditions.

\section{Discussion}

By enhancing the availability of cytosolic NADH through deletion of GPD-catalysed NADH reoxidation, the efficiency of whole-cell reduction of acetophenone, and two-step conversion of racemic 1-phenylethylamine to $(R)$-1-phenylethylamine and (S)-1-phenylethanol was significantly increased. This demonstrates that the cytosolic NADH generated from anabolic reactions under anaerobic conditions was made available for the SADHcatalysed reduction. Conversion of glucose to ethanol is redox neutral as the $2 \mathrm{~mol}$ of NADH generated per mole of glucose in the Embden-Meyerhof-Parnas pathway are oxidized by branching of pyruvate to ethanol, with a theoretical yield of $2 \mathrm{~mol}$ ethanol per glucose. Thus, any additional NADH formed during biosynthesis cannot be oxidized by ADH1 that is the main enzyme responsible for regeneration of $\mathrm{NAD}^{+}$by conversion of acetaldehyde to ethanol. Instead, the NADH formed during biosynthesis is oxidized by GPD1- and GPD2-catalysed reduction of DHAP to glycerol-3-phosphate. Consequently, removal of the glycerol pathway decreases the native NADH oxidation capacity, which then leads to a highly reducing intracellular environment which could successfully be diverted in favour of the recombinant $\mathrm{NADH}$ - dependent oxidoreductase resulting in significantly higher conversion of acetophenone to (S)-1-phenylethanol. Under these conditions it has previously been shown that the limited capacity for NADH oxidation in the gpd1 1 gpd $2 \Delta$ strain results in an inability to proliferate under oxygen-limited conditions [20]. However, it has also previously been shown that over-expression of a recombinant xylose reductase and addition of xylose as external electron acceptor could provide gpd1 1 gpd $2 \Delta$ yeast with the ability to overcome the hurdle, resulting in improved growth and product formation, i.e. xylitol [21, 22]. An improvement in cell proliferation for the gpd $1 \Delta g p d 2 \Delta$ strain during the parallel reaction system under study herein was not observed, thus indicating that the NADH oxidation resulting from the activity of SADH 
Table 3 Initial growth rates, rates of substrate consumption, metabolite formation and calculated NADH balance during whole-cell reduction of acetophenone to (S)-1-phenylethanol

\begin{tabular}{|c|c|c|c|c|c|c|c|}
\hline Strain & $\begin{array}{l}\text { Growth } \\
\text { rate }\left(h^{-1}\right)\end{array}$ & $\begin{array}{l}\text { Glucose } \\
(\mathrm{mM} / \mathrm{h})\end{array}$ & $\begin{array}{l}\text { Ethanol } \\
(\mathrm{mM} / \mathrm{h})\end{array}$ & $\begin{array}{l}\text { Glycerol } \\
(\mathrm{mM} / \mathrm{h})\end{array}$ & $\begin{array}{l}\text { Phenylethanol } \\
(\mathrm{mM} / \mathrm{h})\end{array}$ & $\begin{array}{l}\text { NADH genera- } \\
\text { tion }(\mathrm{mM} / \mathrm{h})\end{array}$ & $\begin{array}{l}\text { NADH oxidation } \\
(\mathrm{mM} / \mathrm{h})\end{array}$ \\
\hline $\begin{array}{l}\text { Control, } \\
\text { VAMT + SADH } \\
\text { (TMB4162) }\end{array}$ & $0.12 \pm 0.02$ & $-74 \pm 9.92$ & $105 \pm 3.69$ & $9.7 \pm 4.52$ & $0.5 \pm 0.04$ & $148 \pm 19.8$ & $115 \pm 5.8$ \\
\hline 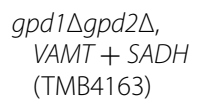 & $0.07 \pm 0.03$ & $-29 \pm 9.20$ & $35 \pm 14.99$ & $0.03 \pm 0.02$ & $1.4 \pm 0.25$ & $69 \pm 18.4$ & $36.4 \pm 15$ \\
\hline
\end{tabular}

Rates were calculated for the first $4 \mathrm{~h}$ of reaction. $\mathrm{NADH}$ balance was calculated from the following assumptions: (i) under anaerobic conditions 2 mol of $\mathrm{NADH}$ are theoretically generated per mole glucose consumed. The value is in reality higher since NADH is also generated in anabolic reactions; (ii) 1 mol of NADH is oxidized per mole of ethanol, glycerol or (S)-1-phenylethanol being produced. During the initial phase of reaction there was also a low amount of oxygen in the bioreactor which also functioned as electron acceptor in respiration. Mean values and standard deviations are calculated from two different whole-cell bioconversions

was insufficient to sustain growth. With this follows that there may still be an over-capacity of available NADH in the system, and that an even higher reduction rate might be achievable by further elevation of SADH activity.

The lower formation of biomass under reaction conditions may facilitate down-stream processing, as this previously have been shown to correlate to reduced extraction yields [11]. It is well known that the gpd $1 \Delta$ gpd $2 \Delta$ strain cannot grow under anaerobic conditions and exhibits hampered growth in aerobic shake flask cultivations-traits attributed to deficiency in the strains NADH oxidizing capacity [20]. This has been considered a limiting factor for the exploitation of the strain for biocatalytic purposes. However, recent findings indiciate that the aerobic growth limitatation can be overcome by applying high aereration rates [28]. This allows for an efficient cultivation of the biocatalyst and thus opens further exploitation of the strain.

When only considering the reduction of acetophenone to $(S)$-1-phenylethanol, the co-substrate yield ( $\mathrm{Y}_{\mathrm{P} / \mathrm{S}}$, moles product/moles glucose) for the gpd1 1 gpd2 $\Delta$ strains over-expressing SADH (TMB4161 and TMB4163) was significantly higher than for the control with intact GPD activity (TMB4160 and TMB4162). This was a consequence of reduced glucose consumption combined with increased availability of NADH and higher carbonyl reductase activity. The yield $\left(\mathrm{Y}_{\mathrm{P} / \mathrm{S}}=0.05 \mathrm{mmol} / \mathrm{mmol}\right)$ was however lower than a previously developed NADPHaccumulating yeast platform system $\left(\mathrm{Y}_{\mathrm{P} / \mathrm{S}}=0.32 \mathrm{mmol} /\right.$ $\mathrm{mmol}$ ), in which glucose metabolism was engineered to improve the efficiency of the NADPH-dependent enantio-selective reduction of a bicyclic diketone [14]. Several advantages follow with the decreased glucose flux, e.g. it results in the mentioned lower demand for glucose for the reaction, as well as lower by-product formation. In particular, less ethanol that can be inhibitory to yeast metabolism, and may contribute synergistically to an increased toxicity of reactants or products, is formed.
Acetophenone was converted to (S)-1-phenylethanol at a significantly higher rate than racemic 1-phenylethylamine was converted to (S)-1-phenylethanol when using either the wild type or the double deletion strains. In addition, no acetophenone was detected at any time of the cascade reactions in the gpd1 $1 g p d 2 \Delta$ strain background, suggesting that it was consumed as quickly as it was formed. Although the increased NADH availability improved the rate of the SADH-catalysed reaction, together the results demonstrate that the rate-limiting step of the two-step conversion of racemic 1-phenylethylamine to $(S)$-1-phenylethanol was the initial transamination reaction in the cascade reaction. This observation has been reported previously for a similar system based on the same $\omega$-TA but instead coupled to a NADPHdependent oxidoreductase from L. kefir [8]. It is likely that the reaction cascade can be improved further by elevating the specific whole-cell transamination activity by for example increasing the intracellular VAMT concentration, which have been shown previously to give a positive effect [29]. It has also been shown that addition of the co-factor PLP of the transamination to the reaction solution can improve the reaction [9]. On the other hand, the capacity for PLP-dependent reactions in yeast was previously calculated to be $1.3 \mathrm{mM} / \mathrm{gdw} / \mathrm{l}$, which is significantly higher than the maximum rate of transamination reaction achieved in the present study [9].

\section{Conclusions}

In the present study it is demonstrated that by decreasing competition from native $\mathrm{NADH}$-specific oxidative enzymes it was possible to increase the activity of the whole-cell biocatalyst for NADH-dependent transaminase-reductase coupled synthesis and at the same time reduce the requirement for glucose to supply intracellular co-substrates and co-factors. The improvement was shown to be valid both for the NADH-dependent onestep conversion of acetophenone to (S)-1-phenylethanol 
as well as for the two-step conversion of racemic 1-phenylethylamine to $(R)$-1-phenylethylamine and $(S)$-1-phenylethanol. The findings made in this work highlight the potential of the gpd1 $\operatorname{gpp} 2 \Delta$ strain as a potent general platform for asymmetric multistep synthesis by (heterologous) enzymes in which at least one of the reactions is NADH-dependent.

\section{Methods}

\section{Chemicals}

Acetophenone, racemic 1-phenylethylamine (1-PEA), and the pure enantiomers $(R)$-1-PEA and $(S)$-1-PEA, all with a purity of $\geq 98.0 \%$, were purchased from Merck (Hohenbrunn, Germany). (R)-1-phenylethanol and $(S)$ 1-phenylethanol were purchased from Sigma-Aldrich (Steinheim, Germany), both with a purity of $\geq 98.0 \%$, and all other chemicals were from VWR (Leuven, Belgium).

\section{Strains and plasmids}

S. cerevisiae strains and plasmids used in this study are listed in Table 1. Escherichia coli NEB $5 \alpha$ (New England BioLabs, Ipswich, MA, USA) was used for subcloning. All strains were stored in $20 \%$ glycerol at $-80{ }^{\circ} \mathrm{C}$. Yeast strains were grown on solid YNB media $(6.7 \mathrm{~g} / \mathrm{l}$ yeast nitrogen base without amino acids, $20 \mathrm{~g} / \mathrm{l}$ glucose and $20 \mathrm{~g} / \mathrm{l}$ agar) before they were inoculated in the preculture as described below.

\section{Molecular biology methods}

Plasmid DNA was prepared using the GeneJET Plasmid Miniprep Kit (Thermo Scientific, USA). Restriction enzymes and T4 DNA ligase were obtained from the same manufacturer. The QIAquick gel extraction kit (QIagen, Hilden, Germany) was used for DNA extractions from agarose. Nucleotides were purchased from Eurofins (Germany). Genetic constructs were checked by sequencing (Eurofins, Germany). Genomic DNA was extracted with a bead-beater (Biospecs Products, Bartlesville, OK, USA) and phenol/chloroform [30]. PCR was performed with DreamTaq Polymerase (Thermo Scientific, Germany).

\section{Plasmid construction}

Genes encoding VAMT [Genbank: AAC78480.1, Uniprot: O82521] [24] and SADH [Genbank: AY161280.1, Uniprot: Q6YBW1] [25] were codon-optimized for S. cerevisiae and ordered from GenScript (New Jersey, USA). The VAMT containing sequence was digested with $X b a \mathrm{I}$, the $S A D H$ containing fragment was digested with $B g l \mathrm{II}$, and the digested fragments were ligated separately or together with YIpOB7 [31] that had been digested with the same restrictions enzymes resulting in plasmids
YIpOB7- SADH and YIpOB7-SADH-VAMT (Table 1). Correct orientation of the inserts and sequences were verified by restriction analysis and sequencing.

\section{Transformation}

S. cerevisiae transformations were performed using the lithium acetate method [32], and transformants were selected on defined medium without amino acids or base. $E$. coli transformations were performed according to the Inoue method [33], and selected on Lysogeny Broth (LB) plates [30] with $50 \mu \mathrm{g} / \mathrm{ml}$ ampicillin (IBI Shelton Scientific, Shelton, CT, USA).

\section{Construction of yeast strains}

Plasmids YIpOB7-SADH and YIpOB7-SADH-VAMT were digested with ApaI and both transformed separately into TMB4132 and TMB4133 yielding the strains TMB4160 (control, YIpOB7-SADH), TMB4161 (gpd14gpd2A, YIpOB7-SADH), TMB4162 (control,

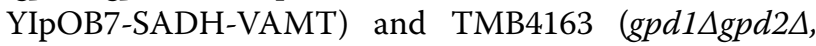
YIpOB7-SADH-VAMT).

\section{Quantitative PCR (qPCR)}

qPCR was performed with a LightCycler Nano (Roche, Switzerland) to determine relative copy number of the heterologous genes in the constructed strains as described previously [8]. The primers were designed to amplify a region of VAMT gene [8]. Genomic DNA was extracted from TMB4160, TMB4161, TMB4162, and TMB4163 using the Yeast DNA Extraction Kit (Thermoscientific, Germany) and the DNA concentrations were measured with Biodrop (Biodrop, Cambridge UK). ExTaq HS polymerase (TaKaRa Bio, Japan) was used in the reaction with DNA-binding dye Eva Green (Biotium, USA).

\section{Enzymatic assay}

Cell extract was prepared with Yeast Protein Extraction Reagent (Thermo Scientific, Pierce, Rockford, USA) according to the instructions provided by the manufacturer. The total protein concentration in cell extracts was determined using the Bradford method [34] with bovine serum albumin (BSA) as standard. SADH activity measurements were performed as described previously [35]. The activity is based on measuring the oxidation of NADH at $340 \mathrm{~nm}$ with an Ultrospec 2100 pro spectrophotometer (GE Healthcare Life Sciences, Sweden). The data were collected with the software program SWIFTII (Amersham Biosciences, Sweden). Cell extracts were diluted until the decrease in absorbance was linear for $5 \mathrm{~min}$, at which point the activity could be calculated from the slope. One unit of activity corresponds to $1 \mu \mathrm{mol}$ NADH consumed per minute at $25^{\circ} \mathrm{C}$. The assay 
contained sodium phosphate buffer $(50 \mathrm{mM}, \mathrm{pH} 7)$, acetophenone $(10 \mathrm{mM}), \mathrm{NADH}(0.2 \mathrm{mM})$, and cell extract (1-30 mg/l total protein).

\section{Analyses}

Growth was followed by measuring the optical density at $620 \mathrm{~nm}\left(\mathrm{OD}_{620}\right)$ using a spectrophotometer (Ultrospec 2100 pro, GE Healthcare Life Sciences, Sweden). Glucose, glycerol, ethanol, and acetate were quantified, as described previously [36], with a high pressure liquid chromatography (HPLC) instrument (Waters, Milford, USA) equipped with an Aminex HPX-87H column (Bio-Rad, Richmond, CA, USA) and a RID-10A refractive index detector (Shimadzu, Kyoto, Japan). The mobile phase was $5 \mathrm{mM} \mathrm{H}_{2} \mathrm{SO}_{4}$ and the temperature and flow rate were kept constant at $45{ }^{\circ} \mathrm{C}$ and $0.6 \mathrm{ml} / \mathrm{min}$, respectively. (R)-1-phenylethylamine, (S)-1-phenylethylamine, $(R)$-1-phenylethanol, (S)-1-phenylethanol, and acetophenone were quantified as described earlier [8], with a HPLC system (Waters, Milford, USA) equipped with a Daicel Chiralcel OD-H column $(4.6 \times 25 \mathrm{~mm}, 5 \mu \mathrm{m})$ and a UV/Vis detector 2489. The mobile phase consisted of 85:15 heptane/propan-2-ol with $0.1 \%$ n-butylamine, the flow rate was $1 \mathrm{ml} / \mathrm{min}$ and samples were analysed at room temperature.

\section{Batch cultivation}

Cells were pre-cultured overnight in $10 \mathrm{ml}$ defined mineral medium supplemented with $2 \%$ glucose [37], in 50-ml Falcon tubes which were placed in a rotary shaking incubator (Innova 43, Germany) set to $180 \mathrm{rpm}$ and $30{ }^{\circ} \mathrm{C}$. To produce yeast biomass of TMB4140 and TMB4141, cells from the pre-culture were inoculated at an $\mathrm{OD}_{620}$ of approximately 0.1 to a baffled shake flask with $50 \mathrm{ml}$ of the same media, and incubated in a shake incubator set to $180 \mathrm{rpm}$ and $30{ }^{\circ} \mathrm{C}$. To produce yeast biomass of TMB4162 and TMB4163, cells from the pre-culture were inoculated at a start $\mathrm{OD}_{620}$ of approximately 0.25 for the double deletion strain and $\mathrm{OD}_{620}$ of approximately 0.04 for the wild type strain, in a 1-L Multifors bioreactor (Infors, Switzerland) containing $500 \mathrm{ml}$ defined mineral medium ( $2 \%$ glucose). Cultivations in the Multifors bioreactors were performed at a temperature of $30{ }^{\circ} \mathrm{C}$, a pH of 5.5 , a stirring of $800 \mathrm{rpm}$ and with $150 \mathrm{ml} / \mathrm{min}$ aeration. Cells were harvested by centrifugation (5000 g for $5 \mathrm{~min}$ ) in the early stationary phase, and subsequently used for the whole-cell bioconversions.

\section{Whole-cell bioconversion}

Cells were transferred to sealed glass vials containing either 15 or $50 \mathrm{ml}$ defined mineral medium with $50 \mathrm{~g} / \mathrm{l}$ glucose at an initial $\mathrm{OD}_{620}$ of 10 . Ergosterol $(0.42 \mathrm{~g} / \mathrm{l})$ and Tween-80 $(0.01 \mathrm{~g} / \mathrm{l})$ were added to the vials in order to facilitate anaerobic growth [38] and thus generation of $\mathrm{NADH}$ from anabolic reactions. Whole-cell bioconversions were semi-anaerobic and took place in a $30{ }^{\circ} \mathrm{C}$ water bath with magnetic stirring. Sampling was made aseptically with a syringe and a needle pierced through a rubber stopper, which also contained an outlet for $\mathrm{CO}_{2}$ produced during glucose assimilation. The reactions were started by addition of the substrate, which were either $7.5 \mathrm{mM}$ acetophenone or $5 \mathrm{mM}$ racemic 1-phenylethylamine.

\section{Additional file}

Additional file 1: Figure S1. Scheme of the studied reactions.

\section{Authors' contributions}

JDK and MC carried out the strain constructions. JDK, CH, and NW performed determinations of relative gene copy number, whole-cell transaminations, enzyme activity assays and chemical analyses, participated in the design of the study, and drafted the manuscript. MC conceived the study and participated in its design and coordination. All authors read and approved the final manuscript.

\section{Author details}

${ }^{1}$ Division of Applied Microbiology, Department of Chemistry, Faculty of Engineering, Lund University, PO Box 124, 22100 Lund, Sweden. ${ }^{2}$ Present Address: The Department of Biotechnology and Biosciences, University of Milano-Bicocca, P.zza della Scienza 4, 20126 Milano (MI), Italy. ${ }^{3}$ Present Address: Evolva, Duggingerstrasse 23, 4153 Reinach, Switzerland.

\section{Acknowledgements}

The Swedish Research Council (Vetenskapsrådet) and the Swedish Research Council FORMAS and are gratefully acknowledged for financial support. Professor Marie Gorwa-Grauslund is gratefully acknowledged for valuable discussions during preparation of the manuscript.

\section{Availability of data and materials}

Data achieved and all constructs made and applied in this work are stored at The Division of Applied Microbiology at Lund University. They are available upon request. In case of interest please contact the corresponding author.

\section{Competing interests}

The authors declare that they have no competing interests.

Received: 29 October 2015 Accepted: 25 January 2016

Published online: 15 February 2016

\section{References}

1. Patel R. Biocatalytic synthesis of chiral alcohols and amino acids for development of pharmaceuticals. Biomolecules. 2013;3:741-77.

2. Höhne M, Bornscheuer UT. Biocatalytic routes to optically active amines. ChemCatChem. 2009;1:42-51.

3. Tufvesson P, Lima-Ramos J, Jensen JS, Al-Haque N, Neto W, Woodley JM. Process considerations for the asymmetric synthesis of chiral amines using transaminases. Biotechnol Bioeng. 2011;108:1479-93.

4. Ni Y, XU J-H. Biocatalytic ketone reduction: a green and efficient access to enantiopure alcohols. Biotechnol Adv. 2012;30:1279-88.

5. Koszelewski D, Tauber K, Faber K, Kroutil W. $\omega$-Transaminases for the synthesis of non-racemic alpha-chiral primary amines. Trends Biotechnol. 2010;28:324-32.

6. Bayer T, Milker S, Wiesinger T, Rudroff F, Mihovilovic MD. Designer microorganisms for optimized redox cascade reactions - challenges and future perspectives. Adv Synth Catal. 2015;357:1587-618. 
7. Klatte $S$, Wendisch VF. Role of L-alanine for redox self-sufficient amination of alcohols. Microb Cell Fact. 2015;14:9.

8. Weber N, Gorwa-Grauslund M, Carlquist M. Engineered baker's yeast as whole-cell biocatalyst for one-pot stereo-selective conversion of amines to alcohols. Microb Cell Fact. 2014;13:118.

9. Weber N, Gorwa-Grauslund M, Carlquist M. Exploiting cell metabolism for biocatalytic whole-cell transamination by recombinant Saccharomyces cerevisiae. Appl Microbiol Biotechnol. 2014;98:4615-24.

10. Parachin NS, Carlquist M, Gorwa-Grauslund MF. Comparison of engineered Saccharomyces cerevisiae and engineered Escherichia coli for the production of an optically pure keto alcohol. Appl Microbiol Biotechnol. 2009;84:487-97.

11. Carlquist M, Wallentin CJ, Warnmark K, Gorwa-Grauslund MF. Genetically engineered Saccharomyces cerevisiae for kinetic resolution of racemic bicyclo[3.3.1]nonane-2,6-dione. Tetrahedron-Asymmetry. 2008;19:2293-5.

12. Schrewe M, Julsing MK, Buhler B, Schmid A. Whole-cell biocatalysis for selective and productive $\mathrm{C}-\mathrm{O}$ functional group introduction and modification. Chem Soc Rev. 2013;42:6346-77.

13. Goldberg K, Schroer K, Lutz S, Liese A. Biocatalytic ketone reduction-a powerful tool for the production of chiral alcohols-part II: whole-cell reductions. Appl Microbiol Biotechnol. 2007;76:249-55.

14. Katz M, Frejd T, Hahn-Hagerdal B, Gorwa-Grauslund MF. Efficient anaerobic whole cell stereoselective bioreduction with recombinant Saccharomyces cerevisiae. Biotechnol Bioeng. 2003;84:573-82.

15. Johanson T, Carlquist M, Olsson C, Rudolf A, Frejd T, Gorwa-Grauslund MF. Reaction and strain engineering for improved stereo-selective whole-cell reduction of a bicyclic diketone. Appl Microbiol Biotechnol. 2008;77:1111-8

16. Carlquist M, Olsson C, Bergdahl B, van Niel EWJ, Gorwa-Grauslund MF, Frejd T. Kinetic resolution of racemic 5,6-epoxy-bicyclo[2.2.1] heptane2-one using genetically engineered Saccharomyces cerevisiae. J Mol Catalysis B-Enzymatic. 2009;58:98-102.

17. Siedler S, Lindner SN, Bringer S, Wendisch VF, Bott M. Reductive wholecell biotransformation with Corynebacterium glutamicum: improvement of NADPH generation from glucose by a cyclized pentose phosphate pathway using pfkA and gapA deletion mutants. Appl Microbiol Biotechnol. 2013;97:143-52

18. Shi A, Zhu X, Lu J, Zhang X, Ma Y. Activating transhydrogenase and NAD kinase in combination for improving isobutanol production. Metab Eng 2013;16:1-10

19. Eriksson P, Andre L, Ansell R, Blomberg A, Adler L. Cloning and characterization of GPD2, a second gene encoding sn-glycerol 3-phosphate dehydrogenase (NAD+) in Saccharomyces cerevisiae, and its comparison with GPD1. Mol Microbiol. 1995;17:95-107.

20. Ansell R, Granath K, Hohmann S, Thevelein JM, Adler L. The two isoenzymes for yeast NAD+-dependent glycerol 3-phosphate dehydrogenase encoded by GPD1 and GPD2 have distinct roles in osmoadaptation and redox regulation. EMBO J. 1997;16:2179-87.

21. Knudsen JD, Carlquist M, Gorwa-Grauslund M. NADH-dependent biosensor in Saccharomyces cerevisiae: principle and validation at the single cell level. AMB Express. 2014;4:81.

22. Liden $G$, Walfridsson M, Ansell $R$, Anderlund M, Adler L, Hahn-Hagerdal B. A glycerol-3-phosphate dehydrogenase-deficient mutant of Saccharomyces cerevisiae expressing the heterologous XYL1 gene. Appl Environ Microbiol. 1996:62:3894-6.
23. Ghiaci P, Norbeck J, Larsson C. 2-Butanol and butanone production in Saccharomyces cerevisiae through combination of a B12 dependent dehydratase and a secondary alcohol dehydrogenase using a TEV-based expression system. PLoS One. 2014;9:e102774.

24. Weber N, Ismail A, Gorwa-Grauslund M, Carlquist M. Biocatalytic potential of vanillin aminotransferase from Capsicum chinense. BMC Biotechnol. 2014; 14:25.

25. Abokitse K, Hummel W. Cloning, sequence analysis, and heterologous expression of the gene encoding a (S)-specific alcohol dehydrogenase from Rhodococcus erythropolis DSM 43297. Appl Microbiol Biotechnol. 2003;62:380-6.

26. Hubmann G, Thevelein JM, Nevoigt E. Engineering of the yeast Saccharomyces cerevisiae. In: Mapelli $\mathrm{V}$, editor. Yeast metabolic engineering: methods and protocols, vol. 1152. New York: Springer; 2014.

27. Yang Y, Zhu S, Piegat TJ, Hua L. Enzymatic ketone reduction: mapping the substrate profile of a short-chain alcohol dehydrogenase (YMR226c) from Saccharomyces cerevisiae. Tetrahedron Asymmetry. 2007;18:1799-803.

28. Knudsen JD, Johanson T, Lantz AE, Carlquist M. Exploring the potential of the glycerol-3-phosphate dehydrogenase 2 (GPD2) promoter for recombinant gene expression in Saccharomyces cerevisiae. Biotechnol Rep. 2015;7:107-19.

29. Weber N. Biocatalytic transamination with recombinant Saccharomyces cerevisiae: Challenges and opportunities. Lund University, Applied Microbiology; 2014.

30. Sambrook J, Russel D. Molecular cloning: a laboratory manual. Cold Spring Harbor: Cold Spring Harbor Laboratory Press; 2001.

31. Bengtsson O. Genetic Traits Beneficial for Xylose Utilization by Recombinant Saccharomyces cerevisiae. Lund University, Applied Microbiology; 2008

32. Gietz RD, Woods RA. Transformation of yeast by lithium acetate/singlestranded carrier DNA/polyethylene glycol method. Methods Enzymol. 2002;350:87-96.

33. Inoue $\mathrm{H}$, Nojima $\mathrm{H}$, Okayama $\mathrm{H}$. High efficiency transformation of Escherichia coli with plasmids. Gene. 1990;96:23-8.

34. Bradford MM. A rapid and sensitive method for the quantitation of microgram quantities of protein utilizing the principle of protein-dye binding. Anal Biochem. 1976;7:248-54.

35. Carlquist M, Frejd T, Gorwa-Grauslund MF. Flavonoids as inhibitors of human carbonyl reductase 1. Chem Biol Interact. 2008;174:98-108.

36. Karhumaa K, Hahn-Hägerdal B, Gorwa-Grauslund M-F. Investigation of limiting metabolic steps in the utilization of xylose by recombinant Saccharomyces cerevisiae using metabolic engineering. Yeast. 2005;22:359-68

37. Verduyn C, Postma E, Scheffers WA, Van Dijken JP. Effect of benzoic acid on metabolic fluxes in yeasts: a continuous-culture study on the regulation of respiration and alcoholic fermentation. Yeast. 1992:8:501-17.

38. Andreasen AA, Stier TJ. Anaerobic nutrition of Saccharomyces cerevisiae. I. Ergosterol requirement for growth in a defined medium. J Cell Physiol. 1953:41:23-36.

39. Gietz RD, Sugino A. New yeast-Escherichia coli shuttle vectors constructed with in vitro mutagenized yeast genes lacking six-base pair restriction sites. Gene. 1988;74:527-34.

\section{Submit your next manuscript to BioMed Central and we will help you at every step:}

- We accept pre-submission inquiries

- Our selector tool helps you to find the most relevant journal

- We provide round the clock customer support

- Convenient online submission

- Thorough peer review

- Inclusion in PubMed and all major indexing services

- Maximum visibility for your research

Submit your manuscript at www.biomedcentral.com/submit
C Biomed Central 